\title{
PROCESSO EDUCATIVO COM GESTANTES E CASAIS GRÁVIDOS: POSSIBILIDADE PARA TRANSFORMAÇÃO E REFLEXÃO DA REALIDADE
}

\author{
Maria de Fátima Mota Zampieri, Vitória Regina Petters Gregório², Zaira Aparecida de Oliveira Custódio3, \\ Maria Isabel Regis ${ }^{4}$, Cássia Brasil ${ }^{5}$
}

\footnotetext{
${ }^{1}$ Doutora em Enfermagem. Docente do Departamento de Enfermagem da Universidade Federal de Santa Catarina (UFSC). Santa Catarina, Brasil. E-mail: mfatima@nfr.ufsc.br

${ }^{2}$ Doutoranda do Programa de Pós-Graduação de Enfermagem da UFSC. Docente do Departamento de Enfermagem da UFSC. Santa Catarina, Brasil. E-mail: vitória@nfr.ufsc.br

${ }^{3}$ Doutora em Psicologia. Psicóloga da Maternidade do Hospital Universitário/UFSC. Santa Catarina, Brasil. E-mail: zaira@ hu.ufsc.br

${ }^{4}$ Socióloga. Docente aposentada do Departamento de Psicologia da UFSC. Santa Catarina, Brasil. E-mail: bel.regis@yahoo. com.br

${ }^{5}$ Acadêmica do Curso de Graduação em Enfermagem da UFSC. E-mail: ca.bs@hotmail.com
}

RESUMO: Pesquisa documental, retrospectiva, que buscou conhecer os significados e a contribuição do Grupo de Gestantes e Casais Grávidos para gestantes, acompanhantes e acadêmicos. Os dados foram coletados em documentos do Grupo no período de 1996 a 2008. Através da análise de conteúdo, chegou-se às categorias: oportunidade para compreensão do processo de nascimento; caminho para autonomia; preparação para o parto, maternidade e paternidade; extensão do círculo social; conhecimento dos direitos; formação e educação em saúde e valorização da interdisciplinaridade. O Grupo foi considerado um fórum de socialização de conhecimentos e de construção de saberes, contribuindo para o pensar crítico e reflexivo, assim como para o fortalecimento dos potenciais e autonomia das gestantes e acompanhantes para conduzir o processo de nascimento e exercer a maternidade e paternidade. Constituiu-se também num espaço de ensino-aprendizagem e de práticas dialógicas, educativas e interdisciplinares. Esse estudo amplia a produção científica e pode servir de subsídio para mudanças nas práticas educativas.

DESCRITORES: Educação em saúde. Gestantes. Avaliação em saúde.

\section{EDUCATIVE PROCESS WITH PREGNANT WIVES AND COUPLES: POSSIBILITY OF REALITY TRANSFORMATION AND REFLECTION}

\begin{abstract}
Documental retrospective research, wich aimed to know significances and contributions of pregnant wives and couples Group for pregnant women, attendants and students. Data were collected in documents of the Group from 1996 to 2008 . Through analysis of data contents the classes found are: opportunity for comprehension of birthing process; way to autonomy; preparation for childbirth, maternity and paternity; extension of social circle; knowledge of rights; formation and education in health; and valuation of interdisciplinarity. The Group was considered a forum of knowledge socialization and construction, contributing to critical and reflexive thinking, potential consolidation and pregnant women and attendants autonomy to conduct childbirth process and to perform maternity and paternity and as space for teach-learning and for dialogic, educative and interdisciplinary practices. This study increases the scientific production and is a support for changes in educative practices.
\end{abstract}

DESCRIPTORS: Health education. Pregnant women. Health evaluation.

\section{PROCESO EDUCATIVO CON GESTANTES Y PAREJAS EMBARAZADAS: POSIBILIDAD DE TRANSFORMACIÓN Y REFLEXIÓN DE LA REALIDAD}

RESUMEN: Investigación documental, retrospectiva, que buscó conocer los significados y contribución del Grupo de gestantes y parejas embarazadas a gestantes, acompañantes y académicos. Los datos recolectados en documentos del Grupo en el periodo de 1996 a 2008. A través del análisis de contenido se formularon las categorías: oportunidad para comprender el proceso de nacimiento; camino para la autonomía; preparación del parto, maternidad y paternidad; extensión del círculo social; conocimiento de los derechos; formación y educación en salud; valorización de la interdisciplinaridad. El Grupo fue considerado un foro de socialización de conocimientos y construcción de saberes, contribuyendo para el pensar crítico y reflexivo, fortalecimiento de potenciales y autonomía de gestantes y acompañantes para conducir el proceso de nacimiento y ejercer la maternidad y paternidad. Espacio de enseñanza-aprendizaje y de prácticas dialógicas, educativas e interdisciplinares. Este estudio amplía la producción científica y puede servir como auxilio para cambios en las prácticas educativas.

DESCRIPTORES: Educación en salud. Mujeres embarazadas. Evaluación en salud. 


\section{INTRODUÇÃO}

O processo educativo é flexível, dinâmico, complexo, social, reflexivo, terapêutico e ético e se constrói a partir das interações entre os seres humanos. Nele, quem ensina aprende e quem aprende, ensina, havendo troca de conhecimentos e experiências, uma vez que cada ser que interage, o faz com suas idéias, valores, atitudes e experiências. O processo educativo é um instrumento de socialização de saberes, de promoção da saúde e de prevenção de doenças. Pode contribuir para a autonomia no agir, possibilitando aos envolvidos tornarem-se sujeitos ativos, na medida em que contribui para valorizar capacidades, auto-estima, autoconfiança e auto-realização. É um instrumento de transformação, de construção e reconstrução da realidade, de posturas e de atitudes, tornando o mundo e a história mais humanos. ${ }^{1}$ Visa resgatar a condição de sujeito, a vocação ontológica do homem na busca de "ser mais" e de se humanizar. ${ }^{2-3}$ Os grupos constituem-se de pessoas com história de vida distintas, mas com interesses semelhantes, que se reúnem para refletir criticamente sobre temas comuns, podendo no coletivo construir saberes conjuntos, superar suas limitações e reconhecer seus papéis sociais. ${ }^{4}$

Nesta perspectiva, o Grupo de Gestantes e Casais Grávidos constitui-se um microambiente interdisciplinar, interativo, dinâmico e complexo; direcionado à promoção da saúde, ao cuidado humanizado e à autonomia dos participantes. É um projeto de extensão gratuito, educativo e interdisciplinar dirigido às gestantes e seus acompanhantes, coordenado por docentes do Departamento de Enfermagem, por uma psicóloga do HU e por uma socióloga. Guia-se por pressupostos da filosofia da maternidade do referido hospital que têm como eixos principais a humanização do cuidado, a autonomia da clientela e a interdisciplinaridade. Além disso, busca seguir os princípios ligados à promoção da saúde que, por sua vez, visam capacitar os indivíduos e empoderá-los para aumentar o controle sobre os determinantes de saúde e, desse modo, manter e melhorar a saúde, propiciar autonomia, mudanças de condições de vida e transformações de posturas, com vistas ao viver saudável. ${ }^{5}$

Ao longo dos doze anos de existência as atividades desenvolvidas foram registradas por meio de fichas de inscrição, avaliações e relatórios, o que possibilitou uma visão empírica da importância do grupo. Contudo, até o momento, há poucas pesquisas científicas realizadas acerca do referido trabalho, o que motivou a realização desta investigação. Neste sentido, procurando ampliar a produção de novos conhecimentos nesta área, o presente estudo teve como objetivo conhecer os significados e a contribuição do Grupo de Gestantes e Casais Grávidos para gestantes, acompanhantes e acadêmicos.

\section{MÉTODO}

Foi realizada uma pesquisa documental retrospectiva. Os documentos utilizados para subsidiar a análise de dados foram as fichas de inscrição e os questionário de avaliação das atividades de monitorização do Grupo, além de depoimentos avaliativos dos acadêmicos participantes. Tais documentos fazem parte do banco de dados do Grupo, desde 1996, início do grupo, até 2008, quando completamos 49 Grupos.

Os dados foram analisados no período de setembro de 2008 a janeiro de 2009. A amostra foi definida pelos critérios de saturação e conveniência. Foram utilizadas 902 fichas de inscrição, as quais determinaram o perfil das gestantes, 500 questionários de avaliação e 20 fichas de depoimentos de acadêmicos de enfermagem, sendo oito de bolsistas. A interpretação foi realizada com base na análise de conteúdo, através das seguintes fases: ordenação e classificação dos dados e análise final. ${ }^{6-7}$ Deste modo, as informações oriundas dos documentos foram lidas exaustivamente, analisadas e, posteriormente, organizadas em sete categorias. São elas: oportunidade para compreensão do processo de nascimento; caminho para a autonomia; preparação para o parto, maternidade e paternidade; extensão do círculo social; conhecimento dos direitos; formação e educação em saúde e; valorização da interdisciplinaridade.

Neste processo foram respeitados os princípios éticos e mantido o anonimato, conforme determina a Resolução 196/96. O projeto foi aprovado pelo Comitê de Ética em Pesquisa da UFSC, sob o parecer $n^{\circ} 256 / 08$. As gestantes, acompanhantes e acadêmicos tiveram seus nomes substituídos por nomes de flores e pássaros.

\section{RESULTADOS E DISCUSSÃO}

A idade das gestantes participantes do grupo variou de 12 a 18 anos (4,98\%), de 19 a 25 anos $(31,12 \%)$, de 26 a 32 anos $(43,41 \%)$, de 33 a 39 anos $(17,04 \%)$ e de 40 a 45 anos (3,36\%). Do total, 66,56 $\%$ eram casadas e $32,61 \%$ solteiras, sendo que as demais eram divorciadas e viúvas. Quanto ao grau 
de escolaridade, $66,53 \%$ tinham o terceiro grau completo ou incompleto, $27,95 \%$, o segundo grau e $5,52 \%$ o primeiro grau completo ou não. Além disso, $77,83 \%$ eram primigestas, $99 \%$. Quanto ao pré-natal, 37,31\% realizavam na rede pública e $56,16 \%$, na rede privada, sendo que $6,53 \%$ não responderam. Os acadêmicos e os bolsistas eram alunos de graduação da quinta fase do Curso de Enfermagem, na faixa etária entre 18 e 21 anos, sendo duas casadas. Três bolsistas permaneceram dois anos atuando no grupo e as demais, um ano.

Das categorias encontradas, cinco dizem respeito à gestante e ao acompanhante, a saber: oportunidade para compreensão do processo de nascimento; caminho para autonomia; preparação para o parto, maternidade e paternidade; extensão do círculo social e conhecimento dos direitos. As outras duas são relacionadas aos acadêmicos: formação e educação em saúde e valorização da interdisciplinaridade.

\section{Oportunidade para compreensão do processo de nascimento}

Para as gestantes e acompanhantes, a participação no Grupo facilitou a reflexão e a compreensão desse novo período da vida. Nesta perspectiva, declararam que esta participação contribuiu para desmistificar e rever crenças e mitos relativos à gestação, ao parto e pós-parto, para ampliar saberes sobre as formas de participação do companheiro/acompanhante, assim como para compreender melhor as transformações ocorridas na gravidez e parto, os cuidados consigo e com o bebê e os direitos da mulher em todo o processo.

A oportunidade de trocar saberes e vivências sobre as etapas do processo de nascimento, de se familiarizar com um ambiente parecido ao que poderá acontecer no parto, de expressar sentimentos e medos, conhecer experiências e refletir sobre situações semelhantes às suas, possibilitou aos participantes, ao construírem coletivamente o conhecimento, fortalecerem seus recursos pessoais, reelaborarem suas compreensões sobre o processo de nascimento, escolherem alternativas saudáveis para vivenciar o processo, e ainda, terem subsídios para a superação de limitações e oportunidades para participar ativamente e com segurança.

Um aprendizado que transformou certos "tabus" em fatos normais da vida. Serviu para desmistificar muita coisa. Esclareceu dúvidas, desmistificando fantasias sobre o parto. Ajudou a nos tranqüilizar e participar da melhor forma possível da gestação, nos tornando mais seguros para o momento do parto e pós-parto (Papoula, Gestante, Grupo 14).

Foi através do grupo que percebi a gravidez como uma experiência natural que pode ser encarada com tranquilidade (Tulipa, Gestante, Grupo 26).

Permitiu que os atores sociais trouxessem sua leitura vivida, e a partir da dialogicidade, solidarizassem suas reflexões e modos de agir, com vistas às mudanças em suas realidades. ${ }^{4}$

As informações, o apoio e o esclarecimento abriram novos horizontes e reflexões (Gérbera, Gestante, Grupo 42).

Permitiu ampliar o conhecimento acerca da gestação, compartilhar dúvidas/inquietações/ansiedades com o grupo e, assim através dessa vivência, viver essa nova experiência com maior tranqüilidade e prazer (Orquídea, Gestante, Grupo 26).

Permitiu dividir, compartilhar experiências, dúvidas e receios próprios deste período e vê-los esclarecidos pelos profissionais. Reforçar conhecimentos anteriores e ampliá-los através das vivências (Miosótis, Gestante, Grupo 45).

Estudos reforçam os achados. Um deles aponta que nos grupos homogêneos, em que são compartilhadas vivências e dificuldades similares, o fato de terem uma linguagem comum possibilita a todos sentirem-se acolhidos, respeitados e, sobretudo, compreendidos mutuamente no que sentem e vivem, fortalecendo-os para superar os problemas. Ao mesmo tempo, essas interações e a experiência de cada componente do grupo oportunizam rever seus próprios referenciais, alterá-lo ou não, quando pertinente. ${ }^{8}$ Desta forma, nesse processo de verbalização das situações ocorridas em suas vidas, os envolvidos podem superar suas meras narrativas, aprendendo ainda mais com as experiências do outro e, assim, capacitarem-se para atuar de forma criativa, superar dificuldades, compreender o processo vivido e reinventar a vida cotidiana, a partir das trocas e da participação crítica. ${ }^{2}$ Assim, a dinâmica grupal, a criação de laços e a troca de vivências comuns, o sentimento de pertencimento e identificação determinados na coletividade fortalecem as capacidades individuais e coletivas, ampliam a visão dos recursos disponíveis e encorajam os indivíduos a buscarem novas estratégias para compreender seus problemas, a fim de minimizá-los ou resolvê-los, além de fortalecê-los para enfrentar os desafios.

No concernente à compreensão do processo, gestantes e acompanhantes reforçam que o Grupo também ajudou a aproximar e concretizar 
situações abstratas e distantes como o pós-parto, tais como, os cuidados com a mãe e com o recémnascido e a prática do aleitamento. Apontam, no entanto, a necessidade de enfatizar mais os conflitos inerentes ao processo bem como maneiras de superá-los, refletir e discutir sobre situações reais trazidas nos reencontros, apesar de compreenderem que o Grupo não dá conta de atender todas as expectativas. Tal fato é ratificado na literatura: o grupo de gestantes enriquece e complementa a assistência pré-natal, não significando que se baste por si mesmo. ${ }^{9}$ Ao abordar essa questão, a pesquisa revela que a curiosidade e a ansiedade das gestantes e acompanhantes em relação ao parto centraliza a atenção deles nesse período e menos no pós-parto, na maternidade e paternidade - situações que parecem estar apenas no imaginário. Nesse sentido, a atividade educativa deveria oportunizar o estabelecimento de formas criativas para trabalhar temas que aumentassem a confiança e habilidade da gestante para conduzir o parto, o pós-parto, os cuidados com a mulher e com o bebê, além de estimular reflexões que ajudassem o casal no exercício da maternidade e paternidade. ${ }^{8}$

\section{Caminho para a autonomia}

Compartilhar conhecimentos e vivências no Grupo sobre o processo de nascimento, segundo as gestantes e acompanhantes, fortaleceu seus potenciais, reduziu medos e deu tranquilidade para seguir o ritmo e os sinais emitidos pelo corpo da gestante, aumentou a sua confiança para fazer escolhas sobre os vários tipos de parto (vantagens e desvantagens), assim como conhecer as técnicas não farmacológicas para minimizar as sensações dolorosas. Além disso, deu mais segurança e esclareceu dúvidas para decidir qual a hora de ir para maternidade e condutas para cuidar de si e do filho e para se posicionar em relação aos inúmeros "palpites" proferidos por pessoas do seu círculo de relacionamento.

Foi de extrema importância. Mudei vários conceitos, principalmente, com relação aos tipos de parto (Camélia, Gestante, Grupo 25).

Além de aprender muito sobre a gravidez, aprendi a olhar as coisas com mais naturalidade e ganhei mais confiança em mim e no que sinto (Antúrio, Acompanhante, Grupo 27).

Aprender como agir no dia do parto (Mosquitinho, Acompanhante, Grupo 49).

Várias dúvidas foram sanadas e muitos medos vencidos (Estrelícia, Gestante, Grupo 44 ).
Obtive uma grande emancipação e segurança, pois conhecendo sobre os tipos de partos, sobre os sinais podemos intervir, decidir ou optar melhor (Violeta, Gestante, Grupo 43).

Esclareceu muitas coisas. Foi um aprendizado muito significativo. Hoje me sinto mais segura em relação ao parto normal e aos cuidados com o meu filho (Amarílis,Gestante, Grupo 46).

O Grupo forneceu subsídios para que a gestante e o acompanhante pudessem refletir sobre as diversas visões e condutas adotadas no processo de nascer, para que pudessem manter, rever e redirecionar as que julgassem necessárias, assumindo, desta forma, o protagonismo deste processo.

A educação em saúde, um dos principais elementos da promoção da saúde, se constitui em um processo político e pedagógico que leva ao desenvolvimento de um pensar crítico e reflexivo e à autonomia do ser humano, ao possibilitar a construção e produção de um saber que propicia a este ser humano ser capaz de propor mudanças e decidir sobre as questões relativas aos seus cuidados, aos de sua família e aos cuidados da coletividade..$^{10}$

Assim, o processo educativo com gestantes, desenvolvido no âmbito grupal, é um instrumento que favorece a autonomia e o protagonismo das gestantes e familiares no processo de nascimento, já que capacita mulheres e homens para fazerem escolhas na gravidez, no parto, no nascimento e no pós-parto. Nesse sentido, segundo programa proposto em Western, Quebec, é importante, a partir dos relacionamentos estabelecidos entre as gestantes e os profissionais, fortalecer as habilidades e confiança da gestante para que ela possa analisar criticamente as informações e decidir conscientemente para conduzir o processo de nascimento. ${ }^{11}$ Contudo, para a efetivação da autonomia, os serviços precisam deixar de deter o poder sobre o processo de nascimento, e não mais, divulgar a idéia de que só eles podem garantir a segurança deste processo, mas confiar e valorizar os conhecimentos e potenciais da mulher.

\section{Preparação para o parto, maternidade e paternidade}

Foi ressaltada pelos participantes a importância da preparação para o parto, em especial, o parto normal e humanizado e as reflexões sobre os diferentes tipos de parto.

Adquiri maior conhecimento acerca da preparação da gestante durante a gestação, parto e pós-parto (Primavera, Gestante, Grupo 27). 
Significou ter a oportunidade de compartilhar com outros pais o processo e me conscientizar da importância da gestação e do parto humanizado (Blue, Gestante, Grupo 18).

A participação nas ações ou atividades de conscientização corporal, a realização dos exercícios respiratórios e de relaxamento, além da troca de saberes sobre os tipos de parto, suas vantagens e desvantagens, bem como sinais de trabalho de parto têm sido apontados pelas gestantes como fundamentais no seu preparo para o trabalho de parto e parto.

[...] divulgação e conscientização de uma nova filosofia de parto, que ainda não é muito divulgada e/ou aceita no meio médico. Creio também que esta filosofia traz benefícios à mãe e ao bebê (Flor de Liz, Gestante, Grupo 25).

Muitas dúvidas foram esclarecidas. Agora é mais fácil tomar alguma decisão na hora do parto (Cerejeira, Gestante, Grupo 50).

Nos últimos anos, as gestantes, conforme os programas e relatos, têm solicitado frequentemente informações sobre parto domiciliar, parto de cócoras ou parto na água, acompanhados por profissionais autônomos ou de clínicas que oferecem esse serviço, sem, contudo, deixar de solicitar uma abordagem sobre a cesariana e suas indicações.

Com as informações pudemos nos preparar melhor para o nascimento, principalmente em relação à valorização do parto normal e ao esclarecimento quanto à cesárea desnecessária. [...] as dicas e informações dos profissionais, a troca de experiências com os outros pais são essenciais nos primeiros dias de vida do bebê. Os exercícios físicos [...] preparar o corpo para esse momento tão especial (Onze horas e Lírio, casal do Grupo 49).

O processo educativo no Grupo tem se configurado como um espaço de discussão, reflexão e fortalecimento de práticas, como o parto normal, que foi medicalizado ao longo da história e, atualmente, é resgatado e estimulado com base nas evidências científicas. Assim, no coletivo são divulgadas e sedimentadas mudanças importantes na condução do processo de nascimento.

O Grupo também tem procurado fornecer elementos para que as gestantes possam compreender que, em algumas situações, o tipo de parto independe de sua vontade, preparando-a para qualquer intercorrência e reduzindo o nível de frustração se o parto desejado não puder ser realizado. Assim, é realizado o "parto possível", aquele que atenderá às suas necessidades e às de seus filhos, de acordo com as indicações médicas e as evidências cientificas. Vale ressaltar que alguns profissionais se utilizam dessa prerrogativa para marcar cesárea, às vezes por comodidade ou por interesses pessoais, havendo a necessidade de se ficar atento, sendo isto objeto de reflexão crítica para outros estudos. Neste sentido, se a indicação for a cesariana, apontam-se algumas possibilidades para que este possa ser vivido de forma humanizada.

O preparo para a maternidade se dá nas trocas de experiências e conhecimentos, reflexões e discussões sobre o tema. De acordo com os depoimentos:

[...] poder estar com varias mulheres na mesma situação e livremente poder falar sobre todos os assuntos que se referem a maternidade (Girassol, Gestante, Grupo 48).

Oito semanas maravilhosas de preparação, carinho, conhecimento. Saibam que a confiança no meu poder de ser mãe cresceu a cada dia depois que passei a freqüentar o curso (Crisântemo, Gestante, Grupo 43).

Além de informações que ajudam na segurança de nosso papel como futuros pais, abriu portas para busca de outras fontes e a fortificar o empoderamento nesse momento tão importante (Gardênia, Gestante, Grupo 47).

A possibilidade de pertencer a um grupo contribui para o fortalecimento ou a criação de uma identidade, de uma referência básica, que permita ao participante localizar-se situacionalmente e elaborar estratégias que possam gerar mudanças. No jogo de iguais, na convivência e conivência grupal, as gestantes e acompanhantes podem, a partir das trocas de experiências e saberes expressos, elaborarem seus sentimentos em relação ao momento vivido e podem gerar novos conhecimentos e aderir os conhecimentos revelados. Essa condição ajuda a consolidar a capacidade de cada participante em acolher e cuidar paternalmente e maternalmente do filho, "além de mobilizar os estereótipos de cada um, o que ajuda cada participante a enfrentar as situações de mudança e de crise, uma vez que tende a 're-significar' suas vivências através do reconhecimento dos outros e de si". 8:12

A participação no Grupo tem estimulado também o contato mãe/ pai e bebê desde a gestação, contribuindo para a formação do vínculo e estruturação da nova família, além de ter oportunizado espaços de discussão e reflexão - entre os casais sobre a paternidade e a maternidade, ampliado os conhecimentos sobre os novos papéis, estimulando a inserção e a participação do pai no processo. 
O grupo de gestantes quebra essa barreira e inclui o acompanhante e o "engravida". Sai "a grávida" entra "o casal grávido" (Copo-de-leite, Acompanhante, Grupo 46).

[...] um despertar. Senti-me mais pai a cada encontro, mais seguro para a gestação e pós-parto para os cuidados do bebê (Cravo, Acompanhante, Grupo 43).

[...] super importante! Meu marido percebeu mais a sua importância no processo, e eu aprendi também como ele pode ser mais participante (Irís, Gestante, Grupo 47).

Estudo similar aponta que a organização de grupos de casais grávidos e de grupos específicos de pais nos serviços de pré-natal facilita a inclusão do pai e acompanhante no processo de nascimento e, sobretudo, no parto. Esse aspecto é contemplado no Brasil, a partir da Lei 11.108/2005, que garante às mulheres o direito à presença de acompanhante durante o trabalho de parto, parto e pós-parto imediato, no âmbito do Sistema Único de Saúde. ${ }^{13}$

No que diz respeito ao acompanhante-pai, o grupo deve levar em conta as especificidades da paternidade, e considerar a colaboração de coordenadores homens, além de incluir pais que já participaram do parto. A divulgação dessas experiências, a discussão sobre a paternidade e a formulação de garantias trabalhistas são condições essenciais para a participação dos pais no prénatal, no trabalho de parto, no parto, pós-parto e nos atendimentos pediátricos. ${ }^{14}$

\section{Extensão do círculo social}

O Grupo oportunizou o encontro entre mulheres e homens que vivenciam o mesmo processo, ampliou e estreitou as relações sociais e as amizades. Ainda, aumentou a rede de solidariedade e de apoio na gestação, que se estendeu após o nascimento, ficando isto evidenciado nos depoimentos, na troca de endereços eletrônicos entre os participantes de um mesmo Grupo e nos encontros realizados após o término das atividades, organizados por ex-participantes de grupos anteriores. O Grupo aproximou a universidade da comunidade, promovendo a saúde e favorecendo a autonomia dos indivíduos.

Uma experiência maravilhosa. A troca de informações com os profissionais e as colegas de barriga foi tudo de bom. Obtive informações que ainda não sabia ou já havia esquecido, mas o melhor foi a amizade que levo daqui. Obrigada pela oportunidade (Lavanda, Gestante, Grupo 40).
Uma iniciativa de caráter social e comunitário que engrandece a área da saúde. A principal qualidade do curso é a sua capacidade em eliminar o medo e proporcionar independência para as famílias. Conhecer os detalhes da gravidez, do parto e do bebê, sejam detalhes técnicos, sociais ou psicológicos, é materializar a saúde pública e a cidadania (Amor Perfeito, Acompanhante, Grupo 26).

A educação tem um impacto positivo sobre a ampliação da rede social dos envolvidos, em face do crescente isolamento entre as gerações na sociedade moderna. ${ }^{15}$ Os grupos permitem a troca de experiência entre os participantes e favorecem a percepção de suas limitações e possibilidades no contexto coletivo. Indivíduos que vivenciam experiências similares, membros de uma determinada comunidade, são capazes de desenvolver planos de ação para modificar aspectos da realidade que podem repercutir na sua saúde, atuando como sujeitos de suas próprias vidas. A formação de grupos de gestantes pode contribuir para maior compreensão de si e do mundo e para a busca das possibilidades e dos recursos para a saúde integral na dimensão individual e coletiva. ${ }^{16}$

\section{Conhecimento dos direitos}

As gestantes e acompanhantes destacam que foram estimuladas a ampliar seus conhecimentos por meio de leituras e bibliografias indicadas e conhecer os recursos de que a comunidade dispõe. Além disso, foram socializadas informações sobre direitos, novas leis que envolvem a gestação, o parto, o puerpério e os direitos reprodutivos e sexuais, possibilitando ao casal e à gestante reivindicarem seus direitos e proporem mudanças na assistência.

Significou ter conhecimentos seguros. Informações de confiança. Serve para encorajar e para conhecer os nossos direitos como mães e acompanhantes (Dália, Gestante, Grupo 46).

O grupo nos dá coragem e força para lutarmos por um processo de nascimento mais humanizado, onde quer que tenhamos optado em ter o nosso parto, nos dando subsídios para buscar nossos direitos (Petúnia, Gestante, Grupo 49).

De posse de seus conhecimentos, a mulher e seu acompanhante podem negociar aqueles direitos ainda em processo de legalização e reivindicar os já conquistados legalmente, exercendo sua cidadania. Os profissionais de saúde têm a responsabilidade de esclarecer os usuários, devendo os gestores procurar criar condições para 
o estabelecimento de uma cultura institucional de informação e comunicação que leve em consideração as especificidades e as peculiaridades de cada área e da população. ${ }^{17}$ Perceber-se e ser percebido como sujeito portador de direitos é fundamental. "A percepção de ser titular de um direito, formal ou não, é um pressuposto para compreender uma situação concreta como injusta, como uma violação ou uma negação de um direito. Aqueles que não se percebem como titulares de um direito, dificilmente podem se sentir merecedores de sua proteção ou promoção ou mesmo achar injusto que esse direito lhe seja negado". $.18: 173$

\section{Formação e educação em saúde}

Esta categoria abarcou os dados apontados pelos acadêmicos, os quais enfatizam a importância de sua participação no Grupo. Para eles, esta participação permite concretizar o conteúdo teórico visto em sala de aula, amplia e aprimora o processo de ensino-aprendizagem na área obstétrica e na promoção da saúde, ao conhecer as dúvidas, medos, necessidades e expectativas apresentadas pelas gestantes. Também permite trocar informações com os profissionais e os participantes sobre o processo do nascimento, além de possibilitar a compreensão do papel do profissional de saúde como facilitador do processo educativo no âmbito coletivo.

As gestantes têm dúvidas e esse grupo alivia um pouco as suas ansiedades e de seus parceiros e família. Também aprendemos muito com elas sobre a gestação. [...] possibilitou uma percepção mais concreta sobre as técnicas de trabalhos em grupo (Sabiá, Acadêmica).

[...] ter ideia das situações futuras da gestação e mesmo daquilo que ocorrerá após a mesma traz bemestar e tranquilidade às pessoas grávidas (Coruja, Acadêmica).

[...] importante o trabalho de orientação realizado. [...] experiência entre elas faz com que se tornem mais confiantes, pois todas estão vivenciando uma mesma situação só que em momentos diferentes (Coleira, Acadêmica).

Para as bolsistas, além do exposto, a atuação no Grupo possibilitou interagir com a comunidade, retribuindo a ela o investimento na sua formação acadêmica, contribuiu para fazer escolhas na sua profissão, fortaleceu sua formação nas práticas educativas coletivas, além de aprenderem cuidando e educando.

Senti-me feliz em compartilhar este momento, tendo a certeza que a educação em saúde em grupo é um cuidado indispensável da saúde pública e privada (Rolinha, Acadêmica bolsista).

Atuar como bolsista favoreceu maior interação com a comunidade, aprimoramento do ensino-aprendizagem, estabelecimento de novas relações e oportunidade de retribuir à sociedade um investimento oferecido, o ensino gratuito. [...] permitiu compreender que além de conhecimentos técnicos, devemos valorizar os aspectos humanos como empatia, interação, sensibilidade, amor, respeito. [...] contribuiu para que eu decidisse sobre a área que pretendo atuar e me especializar futuramente, e auxiliou na escolha do tema do trabalho de conclusão de curso (Arara, Acadêmica bolsista).

O trabalho como bolsista revelou ser uma forma gostosa e interessante de obter melhor compreensão sobre a maternidade e complementar o conhecimento adquirido durante a disciplina sobre a saúde da mulher e da criança (Gaivota, Acadêmica bolsista).

Os grupos de educação em saúde, ao articularem as dimensões sociais, subjetivas e biológicas da vida humana, constituem-se em espaços potencialmente privilegiados para o empoderamento individual e coletivo. "A prática educativo-assistencial não pode ser dissociada da conscientização dos profissionais sobre a sua inserção sócio-histórica, e do espaço de autonomia que ela possibilita para o exercício de novas abordagens para educar e assistir" ${ }^{19: 148}$

\section{Valorização da interdisciplinaridade}

Os acadêmicos ressaltaram que a participação no Grupo foi uma experiência enriquecedora, uma vez que possibilitou a compreensão do papel do profissional de saúde como sendo o facilitador do processo educativo. Além disso, ampliou conhecimentos sobre o processo de nascimento, e sobre a importância do desenvolvimento de trabalhos coletivos para identificar as necessidades e expectativas das gestantes e acompanhantes. Permitiu também desenvolver novas relações interpessoais e compreender como se faz um trabalho numa perspectiva interdisciplinar, além de possibilitar a realização de pesquisas e desenvolver habilidades em outras áreas.

O grupo oportunizou-me compreender melhor a gravidez vivenciada pelo casal; permitiu-me interagir com outros profissionais da área e crescer com suas experiências, conhecer uma instituição hospitalar e suas rotinas, e novas técnicas educativas, aumentando a minha confiança para desenvolver trabalhos grupais. Subsidiou conhecer evalorizar o trabalho interdisciplinar. [...] pude, ainda, adquirir maior habilidade para trabalhar na infor- 
mática. [...] auxiliou-me nas relações com as pessoas e na arte de me comunicar (Águia, Acadêmica bolsista).

Para o sucesso do trabalho em grupo é necessário manter atitude interdisciplinar, ou seja, ter a consciência dos limites e das potencialidades de cada campo de saber, além de abrir-se para o diálogo com outras áreas de conhecimento. Esses são comportamentos fundamentais para integrar saberes e agir de forma recíproca, para desenvolver ações complementares de coordenação e colaboração, e comprometer-se com vistas a um projeto comum, em direção ao fazer coletivo. ${ }^{20}$

\section{CONSIDERAÇÕES FINAIS}

Os resultados desse estudo revelam que o Grupo de Gestantes e Casais Grávidos constitui-se num fórum de reflexão, de diálogo, de construção e de socialização de saberes, propiciando ao casal repensar seus papéis e a importância de eles próprios conduzirem e participarem ativamente do processo do nascimento. Além disso, é uma atividade que contribui para a formação pessoal e profissional e estimula a dinâmica de ensinoaprendizagem e a prática interdisciplinar.

O processo educativo desenvolvido no Grupo é considerado relevante pelos participantes, uma vez que possibilita a quebra de mitos, prepara para o parto, para a maternidade e para a paternidade, dá maior segurança e autonomia ao casal, gerando mudanças de atitudes e comportamentos. De igual maneira, auxilia na formação e estruturação da nova família, estimula o exercício dos direitos e a inserção do acompanhante em todo o processo, contribuindo para a sedimentação desta prática nas instituições obstétricas e para a efetivação da lei do acompanhante no município.

Sendo um trabalho educativo com vocação interdisciplinar, permite compreender que os sujeitos envolvidos estão mergulhados numa teia de relações que se complementam, na qual produzem e são ao mesmo tempo produtos de constantes mudanças, nas dimensões física, emocional e social.

Esse estudo contribui para a produção de novos conhecimentos sobre as práticas educativas com gestantes e casais grávidos, podendo subsidiar o cuidado direcionado a esta população, com base em suas necessidades reais, e também para a prática do ensino na área da saúde, constituindo-se um importante recurso para o processo ensinoaprendizagem.

Por tudo o que se verificou, recomenda-se ofertar ações educativas individuais e coletivas às gestantes e familiares, bem como realizar novas pesquisas sobre essa temática, utilizando outros recortes, novos contextos e atores sociais, ampliando e aprofundando saberes sobre o fenômeno.

\section{REFERÊNCIAS}

1. Zampieri MFM. O processo educativo: interpretando o som da humanização. In: Oliveira ME, Zampieri MFM, Santos OMB. A melodia da humanização: reflexões sobre o cuidado no processo do nascimento. Florianópolis (SC): Cidade Futura; 2001.

2. Alves VS. Educação em saúde e constituição de sujeitos: desafios ao cuidado no Programa da Saúde da Família [dissertação]. Salvador (BA): Universidade Federal da Bahia. Instituto de Saúde Coletiva; 2004.

3. Freire P. Educação como prática da liberdade. $27^{\mathrm{a}}$ ed. São Paulo (SP): Paz e Terra; 2003.

4. Freire P. Pedagogia do oprimido. $41^{\mathrm{a}}$ ed. Rio de Janeiro (RJ): Paz e Terra; 2005.

5. Ministério da Saúde (BR). Secretaria de Vigilância em Saúde. Secretaria de Atenção à Saúde. Política nacional de Promoção da Saúde. Brasília (DF): MS; 2006.

6. Minayo MCS. O desafio do conhecimento. São Paulo (SP): Hucitec; Abrasco; 2002.

7. Bardin L. Análise de conteúdo. Lisboa (PT): Edições 70; 2008.

8. Sartori GSS, Vander Sand ICP. Grupo de gestantes: espaço de conhecimentos, de trocas e de vínculos entre os participantes. Rev Eletr Enferm [online]. 2004 [acesso 2006 mar 12];6(2):153-65.Disponível em http://revistas.ufg.br/index.php/fen/article/ view/821/949.

9. Renkert S, Nutbeam D. Opportunities to improve maternal health literacy through antenatal education: an exploratory study. Health Promot Int. 2001 Dez; 16(4):381-8.

10. Santo R, Penna CM. A educação em saúde como estratégia para o cuidado à gestante, puérpera e ao recém-nascido. Texto Contexto Enferm. 2009 OutDez; 18(4):652-60.

11. Dumas L. Focus groups to reveal parents' needs for prenatal education. J Perinat Educ. 2002 Sum; 11(3):1-9.

12. Lothian JA. Choice, autonomy, and childbirth education. J Perinat Educ. 2008 Win; 17(10):35-8.

13. Brasil. Casa Civil, Presidência da República. Lei $n^{\circ} 11.108$, de 07 de abril de 2005 [Internet]. Brasília (DF): Presidência da República; 2005 [acesso em 02/ jul/2010]. Disponível em: http:/ / portal.saude.gov. br/portal/arquivos/pdf/lei_11108.pdf.

14. Carvalho MLM. Participação dos pais no nascimento em maternidade pública: dificuldades institucionais e motivações dos casais Cad Saúde Pública. 2003; 19(Sup.2):389-98. 
15. Fabian HM, Radestad IJ, Waldenström U. Childbirth and parenthood education classes in Sweden: women's opinion and possible outcomes. Acta Obstet Gynecol Scand. 2005 May; 84(5): p.436-443.

16. Delfino MRR, Patrício ZM, Martins AS, Silvério MR. O processo de cuidar participante com um grupo de gestantes: repercussões na saúde integral individual-coletiva. Ciênc Saúde Colet. 2004 OutDez; 9(4):1057-66.

17. Zobolli ELCP. A redescoberta da ética do cuidado, o foco e a ênfase nas relações. Rev Esc Enferm USP. 2004 Mar; 38(1):21-7.
18. Diniz CSG. Entre a técnica e os direitos humanos: possibilidades e limites da humanização da assistência ao parto. 2001 [tese]. São Paulo (SP): Universidade de São Paulo. Faculdade de Medicina da Universidade de São Paulo; 2001.

19. Silva MA, Oliveira AGB, Mandú ENT, Marcon SR. Enfermeiro e grupos em PSF: possibilidade para participação social. Cogitare. 2006 Mai-Ago; 11(2):143-9.

20. Fazenda IC. Interdisciplinaridade: um projeto em parceria. São Paulo (SP): Loyola; 1991. 